\title{
HUCK BOBTAIL FASTENING SYSTEM - NEW SOLUTION FOR HIGH-STRENGTH LOCKBOLTS
}

\author{
Nenad Fric* \\ Faculty of Civil Engeneering, University of Belgrade, Serbia \\ Dr Dragan Buđevac \\ Faculty of Civil Engeneering, University of Belgrade, Serbia \\ Dr Zlatko Marković \\ Faculty of Civil Engeneering, University of Belgrade, Serbia \\ Jelena Dobrić \\ Faculty of Civil Engeneering, University of Belgrade, Serbia \\ Dr Jovan Isaković \\ Tehnikum Taurunum-College of Applied Engineering Studies in Belgrade, Serbia
}

Alcoa Fastening Systems, introduces the Huck BobTail, representing the most advanced fastening technology to date. Recognized as the next-generation lockbolt, the Huck BobTail delivers 5 times the fatigue strength of conventional nuts and bolts, and is engineered to provide the highest level of strength, reliability, and vibration-resistant performance. Engineered to meet the challenges of a wide range of assembly applications, BobTail offers high performance and easy, quick installation. Key words: Huck BobTail bolts, High strength bolts, Lock bolts

\section{HISTORY OF HUCK BOBTAIL BOLTS DEVELOPMENT}

Lou Huck invented the original Huck fastener in 1944, creating a whole new category of fasteners: Lockbolts (commonly referred to as Huckbolts). Initially designed as an aerospace solution to an aerospace problem, Lockbolt technology quickly spread to the transportation and heavy-equipment industries. Huck developed the C50L fastener for large-diameter applications (1/2" and above) shortly thereafter. The C50L (Grade 5) continues to be the preferred fastener for railroads and railcar manufacturers (Figure 1a).
The next leap in fastener design came during 1990's with the HuckSpin fastener. HuckSpin combined the exceptional design characteristics of basic Lockbolts with sophisticated tooling to create a fast (very fast), efficient joining system while eliminating the pintail waste of previous Huckbolts (Figure 1b).

After more than ten years of rigorous road testing on trucks and trailers Alcoa designed U-Spin (Figure 1c). U-Spin assemblies are installed in pairs in just 10-15 seconds, using the classic Huck "spin on, swage, spin off" installation process. a)

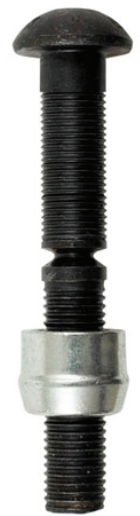

b)

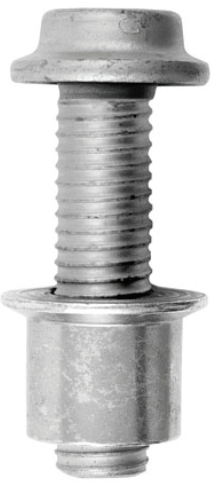

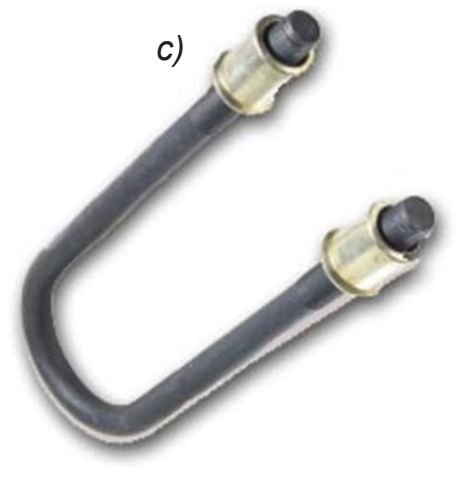

d)

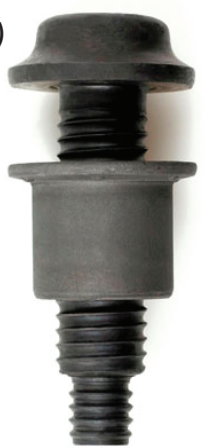

Figure 1: a) C50L Fastener, b) HuckSpin Fastener, c) U-Spin, d) Huck BobTail Bolt 
Equalized clamp force is exerted on each leg during installation, resulting in a level-loaded joint. Because their installation results in permanent clamp, U-Spin U-Bolts eliminate the need for re-torquing [01]. For over seven years it is standard in Volvo vehicle's.

Bobtail Fastening System is designed to replace existing C50L pull-type fasteners, combines rugged light weight installation tools with a precisely engineered fastener to deliver superior value and benefits for the railroad industry (Figure 1d).

It goes above and beyond anything Alcoa Fastening Systems has ever produced for the heavy-duty fastener market and will continue to be the standard "for the long haul". Of course, it is very important that Huck BobTail bolts find their place in construction industry. Aware of this fact, Alcoa engineers designed bolts with larger diameters than it is used in auto industry. With bolts diameter up to $25,4 \mathrm{~mm}$ (1") and appropriate lightweight tooling, considering very fast installation and all other advantages (such as controlled preloading), there is no doubt that Huck BobTail fastening system will find its place on construction industry market.

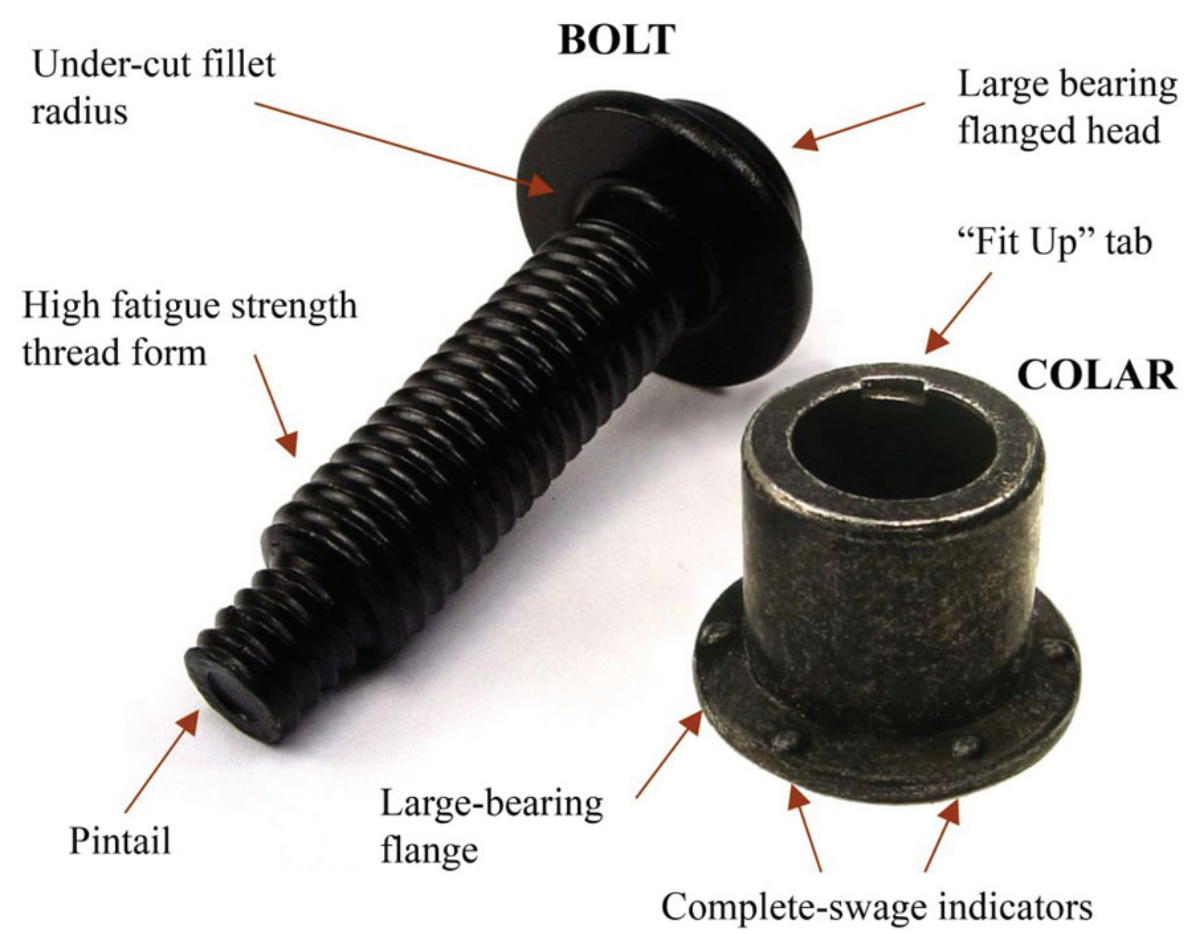

\section{HUCK BOBTAIL BOLTS, COLLARS AND INSTALLATION TOOLS}

Huck BobTail lockbolt is two-piece fastener that consist of bolt and collar (Figure 2). There are two types of bolt heads: round and flanged heads. There are few more types but they are available only on the special request. As about bolt diameters, there are small diameter imperial bolts with diameters: $3 / 16$ " $(4,8 \mathrm{~mm}), 1 / 4 "(6,4 \mathrm{~mm})$, $5 / 16 "(7,9 \mathrm{~mm})$ and $3 / 8 "(9,5 \mathrm{~mm})$, large diameter imperial bolts with diameters: $1 / 2$ " (12,7mm), 5/8" (15,9mm), 3/4" (19,1mm), 7/8" (22,2mm) and 1" $(25,4 \mathrm{~mm})$, large diameter metric bolts with diameters: $12 \mathrm{~mm}, 14 \mathrm{~mm}, 16 \mathrm{~mm}$ and $20 \mathrm{~mm}$. Depending of type of the bolt head and diameter of the bolt there are bolts made in strength classes 5.8, 8.8 and 10.9. Every of these bolts have their collar with appropriate dimensions and strength. All bolts are made of medium carbon steel or alloy steel while collars are made of low carbon steel which is very important due to installation process. Bolts can be anticorrosion protected by zinc plate, Geomet coatings and oil while all collars are zinc plate coated [02].

Figure 2: Huck BobTail Bolts consisting of bolt and collar

The effective diameter of the bolt is reduced, allowing the bolt to stretch more when installed. The fastener has less pre-load loss caused by any seating of the joint. The bolt has been designed to have the same diameter all the way from head to tail to allow easier alignment of joints. The reduced shank diameter allows a larger under head fillet radius to spread the preload of the fastener. It also improves the performance if installed under an angle. Large bearing 
flanged head and large bearing flanged collar eliminates need for hardened washers and adds strength to the joint. Huck BobTail bolts have extended rolled thread which allows determination of minimal grip by stroke length of the toll. The extension of the thread rolled area is possible because the BobTail thread is 6 to 10 times stronger than conventional thread. There is no thread inside the collar, only the "fit-up" tub which allows spun of the collar on the bolt thread before installation. Every collar have installation indicators on its flange. On the end of the pin is so called pintail. Diameter and length of pintail are designed to enable normal operation of the installation tool wich use pull grooves on pintail during installation.

\section{INSTALLATION EQUIPEMENT}

There are many different types of installation systems for the BobTail, dependent of fastener di- ameter, application type and application access. To install BobTail the basic tooling requirement is: powerig - to supply power to hydraulic tools (Figure 3a), installation tool - either pneumatic or hydraulic (Figure $3 \mathrm{~b}$ ) and nose assembly - to match with the fastener and tool [03].

A quick change of nose assembly from the installation nose to the cutter nose (Figure 3c) enables removal of BobTail fasteners using the same tooling system. BobTail cutter nose assemblies are available in same sizes as available bolt diameters. In the beginning, systems for bolt uninstallation was having problems with heat distortion and damage, sparks and spatter. Now, cutter nose assembly works as a side cutting collar cutter (like nut splitter) which showed best results in practise. Usage of collar cutter will enable bolt removal and will not demage oder components.

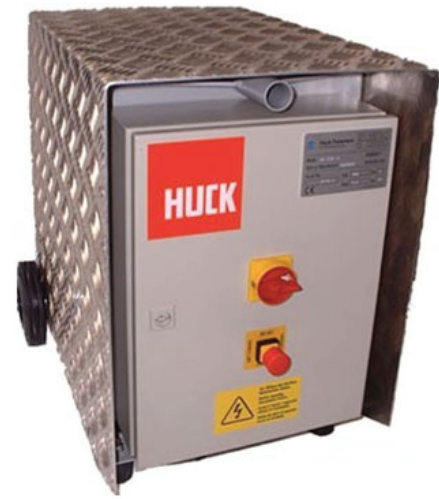

a)

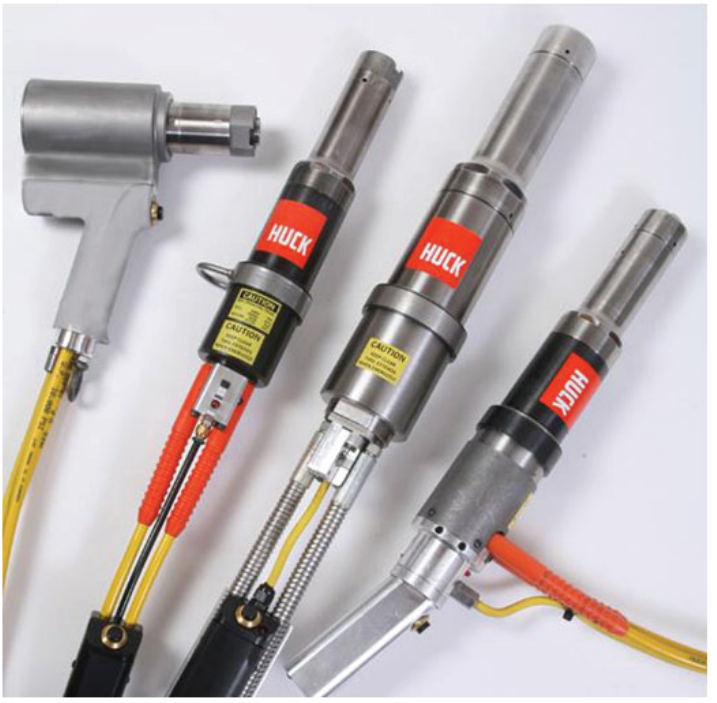

b)
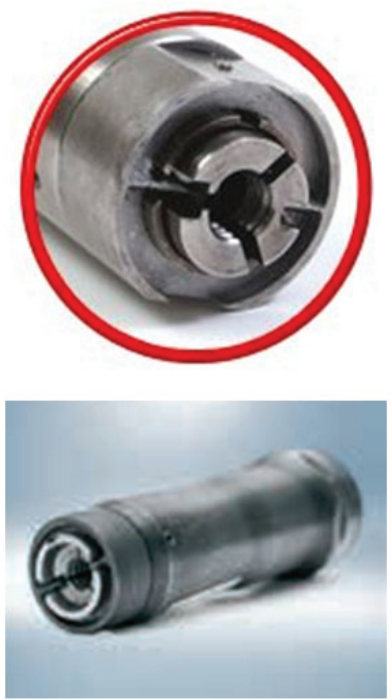

c)

Figure 3: Equipement for installation of Huck BobTail Bolts: a) Powering b) Installation tools,

c) Collar cutter nose asembly

\section{INSTALLATION PROCEDURE AND ITS ADVANTAGES}

The BobTail System delivers a lightening-quick installation cycle time for greater productivity - as fast as two seconds (based on a typical installation of a 5/8" Grade 8 fastener). This quick cycle is due, in part, to the short time required to apply the tool to the pin and initiate the installation cycle. Once the operator engages the trigger, the swage and eject sequence is programmed to complete the cycle without any additional worker input. Installation process is shown on Figure 4.
The pin is inserted into the prepared hole, and the collar is spun onto the pin by "fit-up" tab (Figure $4 \mathrm{a}$ ). The next step in this procedure is applying installation tool to annular pull grooves. When the tool is activated (red light on nose asembly is turned on) (Figure 6a), a puller in the nose assembly draws the pin into the tool, causing the swaging anvil to press on the collar against joint, drawing up any sheet gap (Figure 4b). At a predetermined force, the anvil begins to swage the collar into the pin's lock grooves. Continued swaging elongates the collar and pin, developing precise clamp (Figure 4c). When swaging of the 
collar into the pin lock grooves is complete, the tool ejects the fastener and releases the puller to complete the sequence (Figure 4d) [02]. The installation indicator in the collar flange indicates the BobTail collar has been fully swaged on. A quick visual inspection of highly visible indicators is all that is required to ensure complete installation (Figure 5).

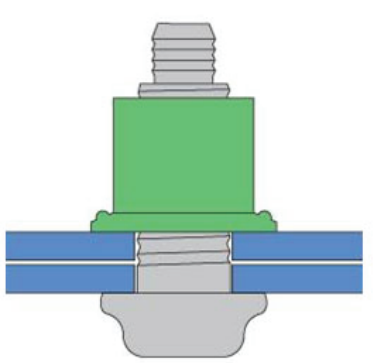

a)

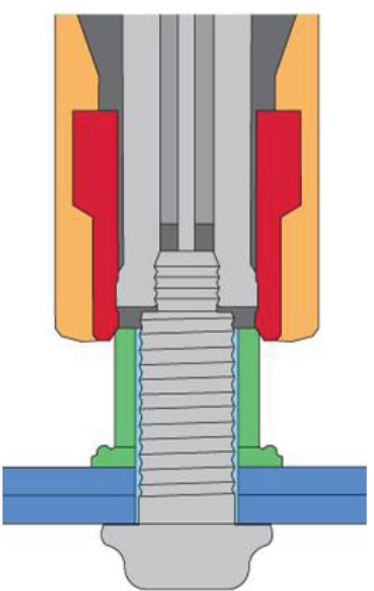

b)

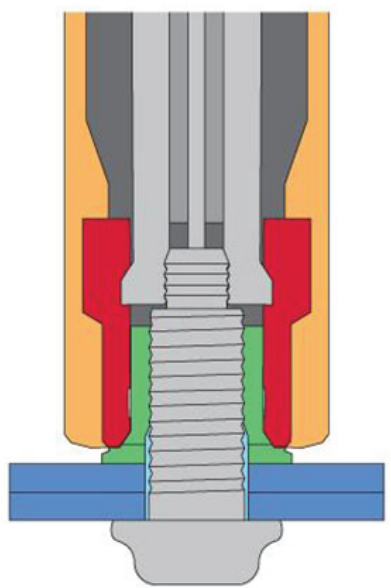

c)
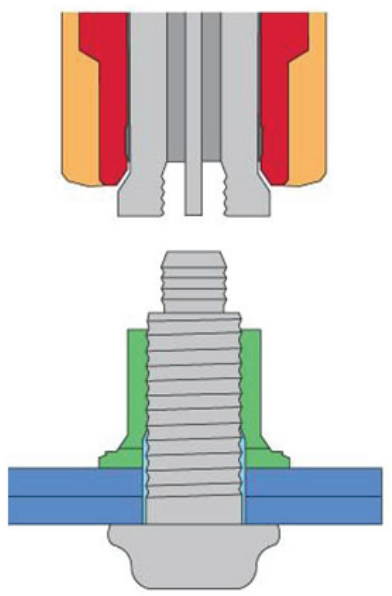

d)

Figure 4: a) Bolt prepared for installation, b) Bolt pintail drawn into the tool, c) Swaging of the collar, d) End of installation process
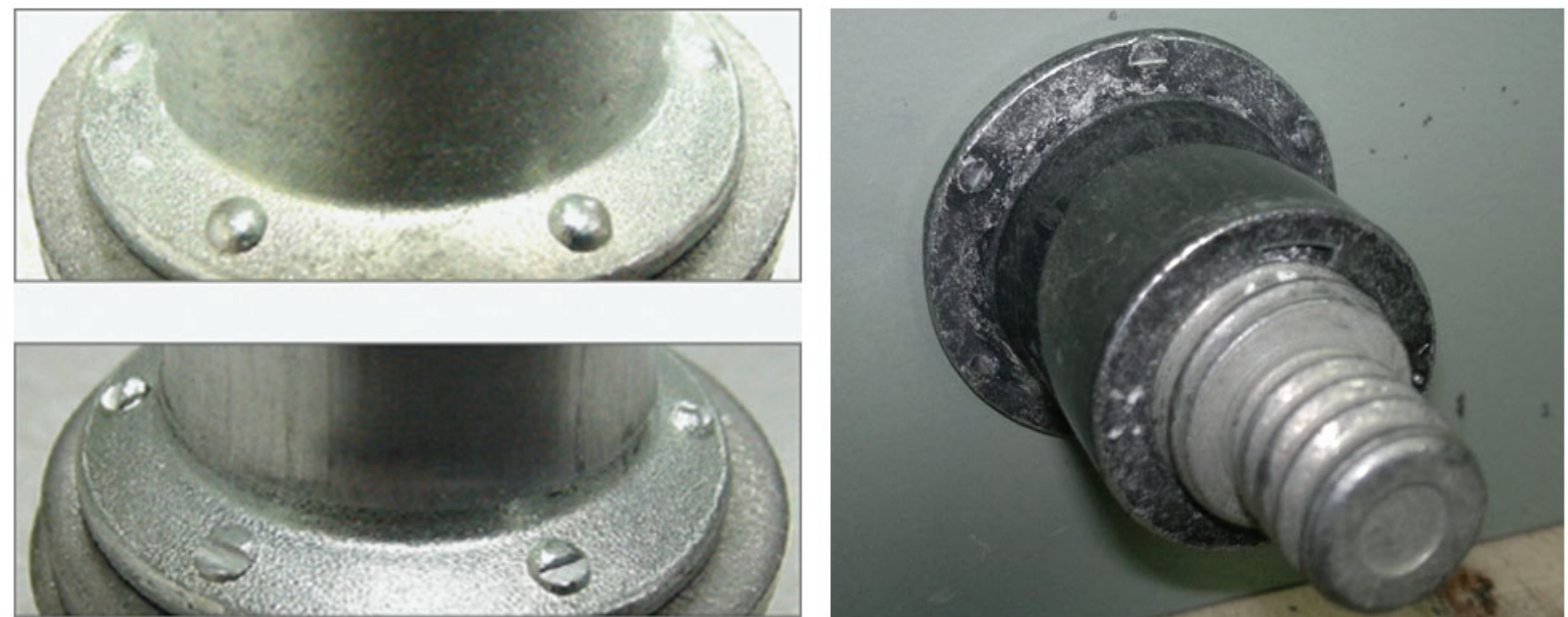

Figure 5: Installation indicators on collar flange before and after installation

In the initial stages of the installation process, the tool engages and pulls on the tail of the fastener. The joint is pulled together before the anvil portion of the nose assembly is forced down the collar. This progressively locks (swages) it into the grooves of the harder pin. The pin and swaged collar combine to form the installed fastener. The squeezing action reduces the diameter of the collar, increasing its length (due to a constant volume of the collar). This in turn stretches the pin, generating a clamp force over the joint [03].

Compared to existing lockbolts and tension controlled bolts [04], the BobTail is designed with a pin-tail which does not require a pin-break. The benefits are reduced waste and weight as well as a clean installation with low installation noise (pin-break at the large diameter bolts causes very loud noise). The lack of a pin-break also ensures a higher corrosion resistance (there is no uncoated area on the bolt) when compared to standard lockbolts with pin-break. There is no initiation points of corrosion and no secondary operations on the bolt after installation.

Absence of a pin-break improved worker hearing safety. Instances of foreign object damage and loose pintail injuries are eliminated. Because BobTail tooling features a smooth, shock-free installation sequence, repetitive stress injuries are eliminated, there are no jolts to the operator's arms and hands and overall safety is increased. 


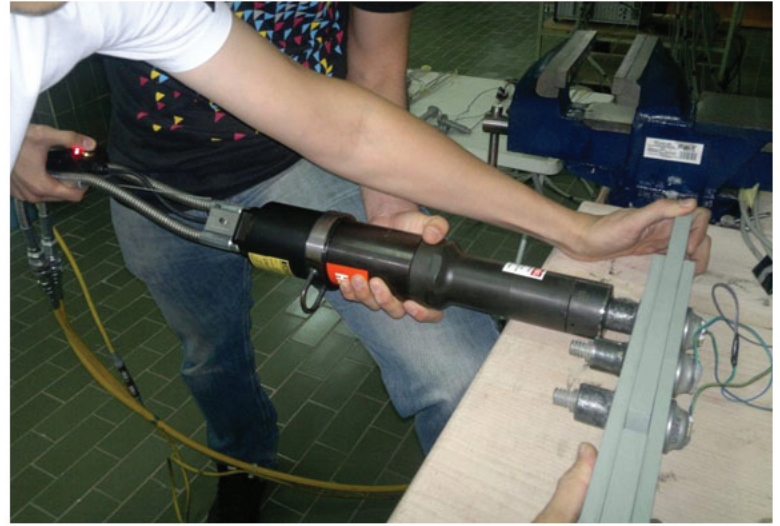

a)

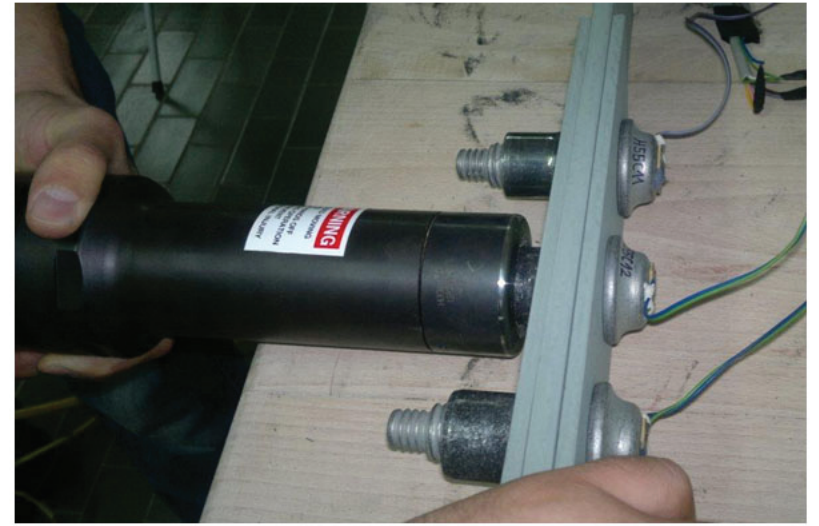

b)

Figure 6: Installation procedure of Huck BobTail bolts diameter $20 \mathrm{~mm}$ : a) red light indicates that the tool is activated b) close-up wiev

Huck Bobtail lock bolts are not subjected to torsion during installation, so they can safely be taken to higher preload values than conventional bolts. Their installation is under direct tension only. Conventional bolts are under a combination of tension and torsion during installation.

Full metal-to-metal contact between collar wall and bolt threads (Figure 7) eliminates the gap usually found between threads in conventional nuts and bolts (in that case contact is made only on $30-35 \%$ of pin and nut thread area). Softer collar material flows between lock-gooves of hardened pin. The gap can lead to loosening in vibration-intensive conditions common to wind turbines, wind towers, bridges etc.

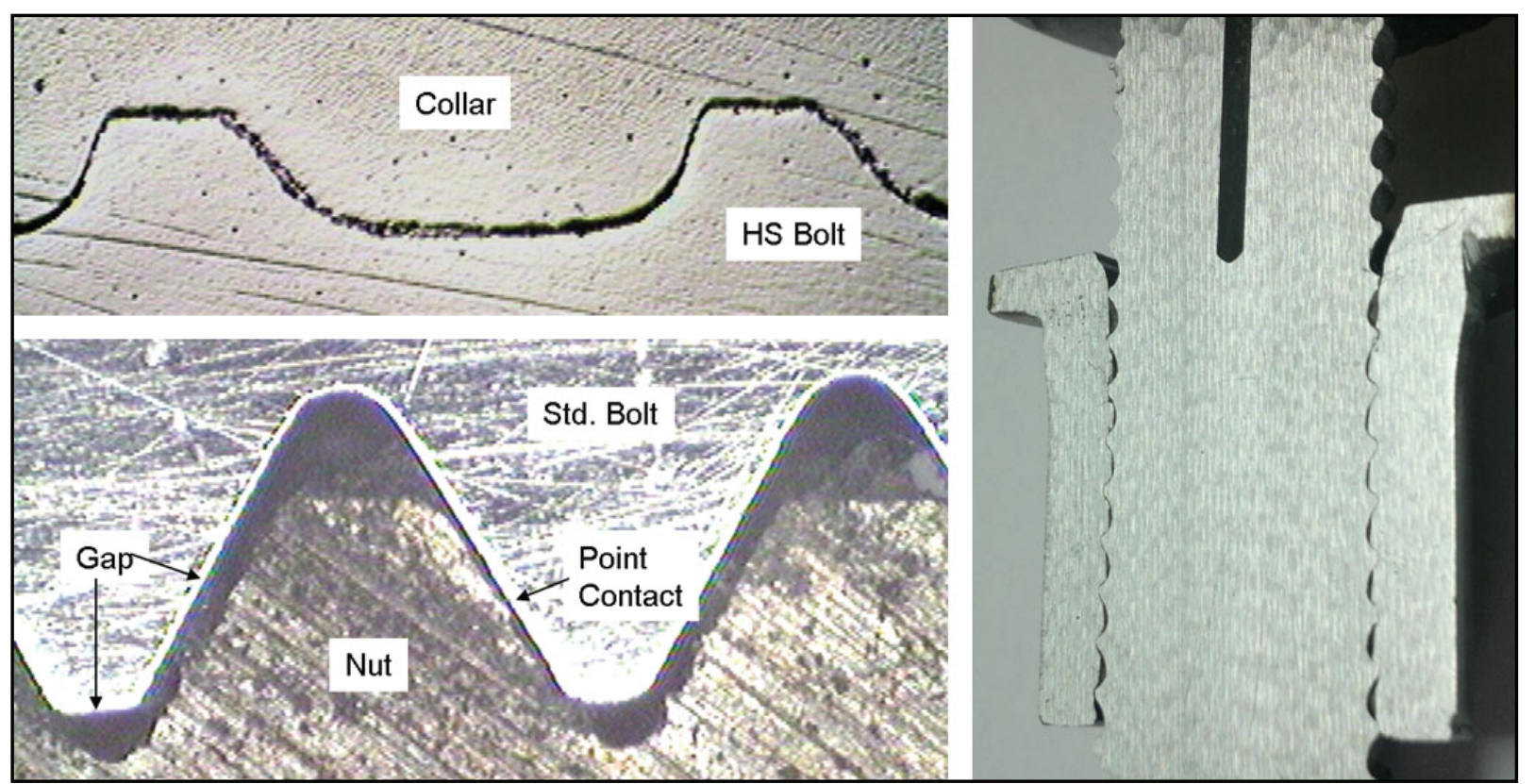

Figure 7: Contact between pin and collar/nut thread

\section{CONCLUSION}

In addition to these advantages and disadvantages of Huck BobTail lock bolts, their price is also very important parameter. As usually, price depends of quantity. Based on the available information a comparative analysis of the bolt prices is made (Table 1). On the one side, there is high strength bolt according to DIN 6914 standard, bolt diameter $20 \mathrm{~mm}$, grade 10.9 and on the oth- er side Huck BobTail bolt [5], diameter $20 \mathrm{~mm}$, grade 8 (due to lack of information on the price for grade 10). Both with grip length $30-40 \mathrm{~mm}$ and both prices based on quantity of 100 pcs. Following a rigorous testing programme, the Huck BobTail lockbolt fastener from Alcoa Fastening Systems has earned the prestigious German national technical approval, otherwise known as allgemeine bauaufsichtliche Zulassungen (abZ), in year 2013 [06]. An Allgemeine bauaufsichtli- 
che Zulassungen (national technical approval) is granted to products and types of construction for which there are either no generally acknowledged rules of technology or DIN (Deutsches Institut Fur Normang e.V.) standards. Declared by DIBt as "maintenance free", the 12, 14, 16, $20 \mathrm{~mm}$ and 1 inch diameter BobTail is now approved to be used in both static and dynamic civil engineering applications. The DIBt test confirmed that a BobTail is maintenance-free during the lifetime of the joint it is fastening, which is not the case when using traditional nut and bolt products. As a result, it can be integrated into a range of applications with complete confidence by civil engineering designers.

As about disadvantages, beside the lack of standards and design criteria, it is very significant that Huck BobTail lockbolts cannot be retightened. Because of that, it is very important for designers to know the exact value of pretension force after installation of the bolt, but also during the life time of the bolt.

Table 1: The comparative analysis of bolt prices

\begin{tabular}{|l|c|c|c|c|}
\hline Type of the Bolt & Bolt [EUR/1pc] & Collar/Nut [EUR/1pcs] & Washers [EUR/2pc] & Total [EUR/set] \\
\hline $\begin{array}{l}\text { Huck BobTail M20, } \\
\text { Grade 8 }\end{array}$ & 1,86 & 1,17 & - & 3,03 \\
\hline $\begin{array}{l}\text { Peiner M20, } \\
\text { Grade 10.9 }\end{array}$ & 3,21 & 1,02 & 0,68 & 4,91 \\
\hline
\end{tabular}

There are many experimental researches with Huck BobTail lockbolts carried out during the last few years in order to remove any uncertainties of their application and enable definition of design criteria. One of these researches started in January 2012 on Faculty of Civil Engineering University of Belgrade and still going on. Main target of this research is to determine installed value of pretension force in high strength bolts and also loses of pretension force during the time, due to type and thickness of zinc silicate anticorrosion protection in friction areas. This experimental research covers two type of bolts: Huck BobTail and high strength bolts according to DIN 6914 standard. All bolts are grade 10.9 and diameter $20 \mathrm{~mm}$ in three different lengths. Samples consisting of three steel plates and three bolts are exposed to two different loads: pretension forces in high strength bolts and 2*106 cycles of dynamic load. Measurement of loses of pretension force is carried out for 8 months and provided valuable information which analyses follows in the next period.

\section{REFERENCES}

1) BobTail, Huck's next generation lockbolt, Alcoa Fastening Systems, 2010, http://www.alcoa.com/fastening_systems/commercial/catalog/pdf/huck/en/AF1032\%20BOBTAIL.pdf

2) http://bayfastening.distone.com/Search/212. all/48/name/cna/

3) http://www.afsglobal.net/afs-news.php?article=1

4) http://bayfastening.distone.com/Search/212. all/48/name/cna/

5) http://www.afsglobal.net/afs-news.php?article=1

6) Nenad Fric, Boris Gligić, Jelena Dobrić, Zlatko Marković: "Wind towers - design of friction connection for assembling sections of tubular steel towers", Journal of applied engineering science, 10(2012)1, 221, 49 - 52, doi:10.5937/jaes 10-1670

Paper sent to revision: 07.02.2014.

Paper ready for publication: 15.03.2014. 